\title{
Examining life course trajectories of lesbian, gay and bisexual people in England - exploring convergence and divergence among a heterogeneous population of older people
}

\author{
Dylan Kneale UCL Institute of Education, UK \\ d.kneale@ucl.ac.uk \\ Robert French \\ Cardiff University, UK
}

(Received August 2016

Revised December 2017)

http://dx.doi.org/10.14301/IIcs.v9i2.425

\begin{abstract}
Because of limitations in collecting sexuality data, there are very few studies that quantitatively explore the life courses of lesbian, gay, bisexual (LGB) individuals. Likewise it is rare that normative patterns of life course trajectories are assessed in terms of their applicability to LGB individuals. We review the current literature on LGB life course trajectories and discuss potential reasons for gaps in the literature. We explore approaches for defining LGB status. We use data from a cohort of people aged 50 and over (English Longitudinal Study of Ageing) to explore the tempo and occurrences of transitions to adulthood and to older age, and establish some of the differences based on sexual orientation. We examine the connecting health behaviours and life course turning points that may explain some of the differences described above. We show that while the first quartile of transitions to adulthood are experienced fairly uniformly by sexual orientation, differences open up thereafter. LGB people's life course trajectories are marked by different patterns of care, with LGB people less likely to provide care in the form of parenthood, but potentially more likely to provide care earlier to close friends or relatives. Analyses of connecting events suggest that LGB life course trajectories may be marred by higher levels of volatility, including higher risk financial hardship. Caveats to these results are outlined in full in the paper.
\end{abstract}

\section{Keywords}

LGB; life course; ageing; adulthood 


\section{Introduction}

The life course approach was developed to explore normative trajectories, which can then be used to contrast different patterns of development by individual characteristics. This approach has been used to establish the similarities and differences in trajectories by gender, socioeconomic status (SES), ethnicity and many other characteristics. Because of limitations in reporting of sexuality and other issues, there are very few studies that quantitatively model the life courses of LGB individuals. Likewise it is rare for normative transition markers to be evaluated in terms of their applicability to LGB individuals. Here, we aim to contribute to plugging this evidence gap through exploring descriptive accounts of a cohort of people aged 50 and over and their experiences of transitions to adulthood and to older age, and to explore some of the differences based on sexual orientation. We also examine some of the connecting health behaviours and life course turning points that may explain differences in the transitions described above. The LGB acronym covers a heterogeneous spectrum of people and each of the broad groups within the LGB spectrum may share some commonalities in experience; although conversely may differ from one another due to the impact of cumulative advantage and disadvantage (Dannefer, 2003), as well as psychological stress resulting from differential exposure to homophobic or heteronormative treatment (minority stress; (Meyer, 1995)). Any reductive technique - as is the case for almost all results from quantitative research - will underestimate heterogeneity in experience and need. Nevertheless, identifying some common or dominant experiences does provide a starting point for identifying areas for future research. For analytical reasons, in this paper we focus on LGB people although do recognise that transgender people are also likely to experience different life course trajectories, and posit that within this broad category there will exist a plurality of experience.

We begin by considering the current literature on how life course transitions (transitions to adulthood, transitions to ageing, and other life course events) have been applied to LGB life course trajectories. This is followed by a discussion of our methods, including a description of the ELSA (English Longitudinal Study of Ageing) dataset, an explanation of the derivation of variables including
LGB status and a description of the modelling of the Kaplan Meier survival curves and accelerated failure time models for life course events. We finish with a discussion of the three key findings - LGB differences in terms of parenthood, caring and sexual assault), the limitations of the study, and a suggestion for future directions in methods for LGB life course research.

\section{Background}

\section{Life course events}

\section{Transitions to adulthood}

Research on transitions to adulthood has focused on studying the timing and context of experiencing the 'big five' transitions to adulthood, which have notionally included: "leaving school, starting a full-time job, leaving the home of origin, getting married, and becoming a parent for the first time" (Shanahan, 2000, p667). While the exact definition of these transitions has changed across studies, and has tended towards broader status characteristics around leaving education, entering paid employment, independent living, and stepping into family formation and parenthood (Schoon, Chen, Kneale, \& Jager, 2012; Schulenberg \& Schoon, 2012), the substantive nature of these transition markers has remained remarkably constant and they have been used to examine transitions across diverse populations.

Developmental theories of the transition to adulthood have recently speculated on the emergence of a defined period between the ages of 18 and 25 years, where young people explore different social roles, which can be non-normative and temporary, before acquiring some of the more enduring responsibilities of young and later adulthood (Arnett, 2000). Since then, others have questioned the equity of different social groups' experiences of this period of role exploration (Bynner, 2005), and a number of these markers of adulthood individually have been associated with considerable degrees of socioeconomic polarisation in the UK (Kneale \& Joshi, 2010; Lupton et al., 2009; Sigle, 2016) and beyond (Rindfuss, Morgan, \& Offutt, 1996; Rogan \& Reynolds, 2015). Studies taking a more person-centred approach have also confirmed that those from more disadvantaged backgrounds are likely to have completed a number of transitions to adulthood in rapid succession precociously compared to more advantaged peers (for example Schoon et al., 2012), while gender is 
also identified as a prime antecedent of different transition patterns (Bynner, 2005; Schulenberg \& Schoon, 2012). Other characteristics, both innate and structural, such as ethnicity, have also been investigated (Arnett, 2003; Bynner, 2005) and such research has prompted critical discourse around variations in the meaning of adulthood across different groups (Arnett, 2003). Others have been critical of the way in which transition patterns that are dominant within minority groups have nevertheless been considered deviant due to their divergence from patterns observed among majority groups (Geronimus, 2003, 2004). In the case of other minority groups, and particularly the group in focus in this paper - LGB people - less is understood about how the transition across these 'big five' markers of adulthood varies compared to heterosexual peers. This means that critique and debate around how and when groups differentiated by sexual orientation experience transition to adulthood using these markers, and the appropriateness of the markers themselves, is underdeveloped.

\section{Life course turning points and connecting events to older age}

In many ways, we are still at the cusp of understanding whether LGB lives follow trajectories of divergence or convergence compared to their non-LGB peers. Nevertheless, some common themes have emerged in the extant literature that suggest potentially divergent life course trajectories may emerge early on through LGB people's greater risk of experiencing difficulties in their relationships. US data suggests that non-heterosexual young people receive less parental support during the (chronological) period of transitioning to adulthood than their heterosexual peers (Needham \& Austin, 2010). This lower level of parental support is also found to explain health disparities occurring early on in life such as increased risks of depressive symptomology and substance abuse (Needham \& Austin, 2010). Other social relationships may also be vulnerable to strain, and LGB people experience substantially higher levels of bullying than non-LGB people, as well as lower levels of life satisfaction during teenage years (Henderson, 2015). This latter study supports the minority stress hypothesis, which states that identifying as a minority group, or having this identity ascribed by others, can lead to unequal treatment. This may result in psychological stress, manifested through higher incidence of mental health problems, including depression and anxiety (Lehavot \& Simoni, 2011; Meyer, 1995, 2003), and higher incidence of linked outcomes, including suicide, substance abuse and affective disorders (Meyer, 2003). In later adulthood, these unequal starts may continue through into different ageing 'processes' among LGBT people (for example Harrison, 2006), and may also help to explain why and how LGB people enter into older ages with different levels of 'capital'. Previous studies have found that LGB people experience ageing with different forms of social capital, being much more likely at age 50 to be single and to have experienced multiple cohabiting relationships of shorter duration than non-LGBT people, a potential reflection of inadequate support services and societal hostility towards same-sex relationships over their earlier life course (Kneale, Sholl, Sherwood, \& Faulkner, 2014; Meyer, 2003). Different levels of social capital are one factor that places LGB adults at greater risk of negative physical and mental health conditions (Fredriksen-Goldsen et al., 2013). UK data also suggests that LGB people of all ages may have greater levels of income and wealth instability, with gay men and bisexual women being much more likely to be in receipt of means tested benefits (Uhrig, 2015) and in later life may be less able to draw upon property wealth as a source of income during retirement (Kneale, 2016).

However, many open questions remain in terms of our understanding of normative LGB life course patterns during adulthood (Furstenberg, 2010). Many key life course events may be significant both in their own right and in terms of how they influence the transition to adulthood and beyond, and some of these may be more pertinent than the standard measures when considering how LGB trajectories differ from the heterosexual norms. Experience of societal hostility and inequality in opportunities may be associated with life course volatility as exhibited by higher exposure to risky behaviours, encountering more dangerous situations, including exposure to physical and sexual violence, and more challenging circumstances, such as poor health or financial hardship; these in turn may see LGB people reach older age with systematically different levels of acquired advantage and disadvantage.

\section{Transition to older age}

In addition to the transitions to adulthood described above, it is unclear whether LGB 
individuals fit into the normative patterns of transitions to older age. Biological markers of ageing can be pronounced and revolve around the extent of diminution of functional capability (Kuh \& NDAP Network, 2007). The social markers of transitions to older age are less defined but may include retirement (Kim \& Moen, 2002), assumption of caring responsibilities (Hughes, Waite, LaPierre, \& Luo, 2007; Utz, Carr, Nesse, \& Wortman, 2002), changes in marital status (and particularly experiencing widowhood) (Chudacoff \& Hareven, 1979), as well as experiences of serious ill-health or infirmity and the development of care needs (French \& Steele, 2015; Settersten Jr \& Mayer, 1997). Although the very notion of such transition markers of ageing has been criticised because such named events are often negative and are assumed to be additive in nature (Settersten Jr \& Mayer, 1997), a similar situation prevails as above where the literature exploring whether, how and why LGB ageing patterns differ is underdeveloped. This has led to older LGB people being characterised as societally invisible and consequently being underserved by formal systems of support (Fredriksen-Goldsen \& Muraco, 2010).

Where LGB experiences of older age have been considered, many suggest that older LGBT people's experience of ageing is marred by some of the same discrimination observed in younger years (Addis, Davies, Greene, MacBride-Stewart, \& Shepherd, 2009). Greater contact with care providers through institutional or domiciliary care can be particularly stressful for older LGBT people who may come into contact with heteronormative or homophobic attitudes and behaviours among care providers or other care recipients (Addis et al., 2009; Musingarimi, 2008; Phillips \& Marks, 2008). However, while there are many who emphasise disproportionately negative circumstance in older age for LGB people (Green, 2016; Musingarimi, 2008; Potter, Bamford, \& Kneale, 2011), others emphasise the diversity of experiences (Hammack \& Cohler, 2011; Muraco \& Fredriksen-Goldsen, 2016). Nevertheless, gaps remain in the body of evidence and many studies that aim to take a life course approach are based on narrative accounts collected among LGB people, as opposed to studies that offer comparative analyses. Therefore, while some of the evidence above suggests that LGB people may be at risk of unequal starts in life as well as disorganised patterns of ageing, there has been little extant research exploring how LGB trajectories may differ across the big five markers of transition to adulthood and how potential inequalities persist into older age.

\section{Methods and data \\ Data}

There are now a growing number of data sources that allow researchers to identify sexuality. However, the English Longitudinal Study of Ageing (ELSA) was one of the first to measure older people's lifetime same-sex experiences and desires (Steptoe, Breeze, Banks, \& Nazroo, 2013) ${ }^{1}$. ELSA is a longitudinal study focused on older people aged 50 and over and is the prime source of quantitative insights into the ageing process in the UK. The study originally recruited around 12,000 respondents, with the first full wave of data collection occurring in 2002; since then, the panel has been replenished three times to maintain representation of younger age groups (50-55), so that in 2012, in the sixth wave of data collection, data were collected from 9,169 core study members. This sweep included data on sexual relationships and activities from a total of 6,201 respondents. The data in this paper also draw upon a life course history module that was fielded in wave 3 (2006), with data collected from 7,855 individuals. Much of these data were collected through computer-aided personal interviews, although some questions were completed through a 'life grid'. Collecting retrospective data in this way does introduce the risk of measurement error in terms of participants' ability to accurately recall past events (recall bias) compared with a more prospective design. However, there is little reason to suspect that this potential error would be distributed unevenly across $L G B$ and non-LGB people.

\section{Identifying LGB older people in ELSA}

The ELSA questionnaire asked respondents to describe their same and opposite sex attraction and separately their sexual experiences during their lifetime. Respondents were given the option of reporting lifetime desires or experiences that were either (1) exclusively for/with the opposite sex; (2) mainly for/with the opposite sex with some for/with the same sex; (3) equally for/with the opposite and same sex; (4) mainly for/with the same sex with some for/with the opposite sex; (5) exclusively for the same sex; in addition to (6), a no desire/experience category ${ }^{2}$. Of those with any 
sexual experience, $94.9 \%$ of men and $96.7 \%$ of women reported exclusively heterosexual sexual experiences over their lifetime; in comparison, of those who reported any sexual desires over their lifetime, $94.6 \%$ of men and $93.5 \%$ of women reported exclusively heterosexual attraction (estimates not restricted to those with life course history data). Measures of sexuality over the life course provide unique insight but also raise several challenges in these data. Firstly, the sampling strategy employed in creating the ELSA study did not oversample LGB people (or other minority populations such as ethnic minorities (Lee, Nazroo, O'Connor, Blake, \& Pendleton, 2015)), and regardless of the derivation strategy chosen to identify potential LGB respondents, the relatively small sample does impinge on generalisability to the wider older LGB population. Secondly, the inclusion of a 'lifetime' indicator means that in addition to increasing the potential for recall error, we are also unable to identify when same or opposite sex behaviour took place.

In this study we examine differences between 'heterosexual' respondents (referred to as non-LGB from this point onwards) and a combined category that includes 'lesbian, gay and bisexual' respondents (referred to as LGB from this point onwards). The 'LGB' category is formed of those respondents who report mainly and exclusively same-sex experiences or attraction and those respondents who report experience or attraction equally to the opposite and same sex over their lifetime. In addition, to account for those respondents with same-sex experiences that may only have occurred later in life, we also include those respondents with 'some' same-sex experience in our LGB category; this approach means that we do not include respondents who report some same-sex attraction at some point in their life time (and no experience) as being LGB. The small sample of LGB older people we identify precludes exploration within the LGB spectrum. The data collected allow for a plurality of potential approaches that could be taken in defining individuals as LGB, which are explored elsewhere (see supplementary materials and discussion further in the paper).

\section{Deriving measures of life course experiences, covariates and analytical sample}

In this study we examine transitions to adulthood using the 'five big markers' of adulthood (first parenthood, cohabiting partnership, paid employment, exits out of the parental home and out of full-time education). Some logical inconsistencies were observed in these variables, for example first births occurring during infancy, and cases with these logical inconsistencies were dropped $^{3}$. We also examined life course turning events through exploring the age at which respondents reported first being exposed to risky or harmful situations. These reflected both socioeconomic risk (first experience of financial hardship), risky health behaviour (age first smoked on a daily basis), and other traumatic events (age at which respondents experienced physical assault and sexual assault (including harassment and rape)). Finally, in examining ageing transitions, we derived variables reflecting the age at which respondents reported first experiencing a serious illness or disability, and the age at which they first provided care to a close friend or family member. We also derived a variable reflecting age at retirement based on reports collected from waves 1-6. In keeping with the descriptive, theorygenerating, account presented here, we do not introduce a number of covariates that may explain our results. In addition to our main covariate of interest - LGB status - we only introduce age group and gender as potential confounding variables.

\section{Modelling strategy}

First we examine the age at which the first $25 \%$ and $50 \%$ of respondents experienced life course events by LGB status, using Kaplan-Meier productlimit estimate of the survivor function (Kaplan \& Meier, 1958). We develop these analyses further through constructing regression models to account for age and gender as potential confounders. Cox's Proportional Hazards specifications were rejected because we did not have support for the proportional hazards assumption. After exploring the shape of the hazard (of experiencing the event), we then tested a number of the accelerated failure time model specifications, using information criterion and Cox-Snell residuals to evaluate overall model fit (Jenkins, 2005). We found that the loglogistic specification provided the best fit, and in some cases provided the only possible fit. For consistency, this specification was used in all regression models.

Missing data and consequent restricted sample size was problematic in these analyses. The number of LGB participants identified was affected by three 
factors. Firstly, not all respondents at wave 6 were present at wave 3 due to wave non-response and replenishment of the ELSA sample since wave 3; and many of those present at wave 3 had attritted by wave 6 (either temporarily or permanently, including respondents who had died). Secondly, both the life course history and sexual behaviour modules achieved substantially lower response rates than for their respective waves as a whole. Thirdly, there were item non-response and logical inconsistencies. Despite missingness and attrition being substantial challenges, and representing caveats to the findings presented, we do not impute missing values, primarily because it is likely that this missingness is not at random. Furthermore, sensitivity analyses suggested that where data was observed at wave 6 but not wave 3 in our analyses, this was not patterned by LGB status. To boost the power of our analyses, in analysing ageing transitions and life course turning events we allow the analytical sample to vary across models.

\section{Results}

Our results begin by examining frequencies for life course events by sexual orientation (table 1). We firstly discuss the markers of transition to adulthood (left education and entered labour marker, left parental home, cohabiting partnerships, parenthood), followed by other key turning points (daily smoking, financial hardship, physical assault, sexual assault) and finally markers of ageing (retirement, development of serious illness or disease, provided care for relative or close friend). We then show how the tempo of experiencing the big five markers of transition to adulthood differs by sexual orientation (table 2), and examine whether those differences are robust to the impact of age group and gender (table 3). We then consider how the timing of the four life course turning points (physical assault, sexual assault, severe financial hardship, daily smoking) differs by sexual orientation (table 4). Finally, we consider the tempo of markers of reaching older age (retirement, development of serious illness or disease, providing care for relative or close friend) (table 5) and whether patterns by sexual orientation remain significant once we control for age and gender (table 6).

\section{Life course events occurrence by sexual orientation}

Examining the breakdown by sexual orientation of major markers of transition to adulthood (table 1 ), shows that by the age of 50 LGB people and nonLGB people are equally likely to have experienced almost all of these transitions. The exception to this rule is parenthood, which is more frequently experienced among heterosexual people. However over $70 \%$ of those identified as LGB have nevertheless experienced parenthood by the age of 50 , suggesting that even this marker of family formation holds considerable salience for older LGB people. Most markers of older age are also experienced uniformly, with retirement and the development of a serious illness or disease being experienced as frequently among LGB as non-LGB people aged 50 and over. This suggests that there are some similarities among the life course trajectories of LGB and non-LGB people, although we do find that LGB people are more likely to provide care for close friend or relative than nonLGB people. Examining life course turning points and health events, shows greater differences by sexual orientation than observed for the measures of transitions to adulthood and ageing above. The proportions experiencing physical assault are not significantly different for LGB and non-LGB. However, there are indications that LGB people are more likely to reach older age having experienced traumatic events including severe financial hardship (17.4\% among non-LGB compared to $24.6 \%$ among LGB people) and sexual assault (6.0\% among nonLGB compared to $11.8 \%$ among LGB people). 
Table 1: Descriptive statistics displaying sample size, demographic characteristics and experiences of transition markers by LGB status: weighted percentages and Ns (unweighted obs in parentheses).

All data weighted by wave 6 weights and standard errors account for sample design.

\begin{tabular}{|c|c|c|c|c|}
\hline & & Heterosexual & $\begin{array}{c}\text { Lesbian, gay or } \\
\text { bisexual }\end{array}$ & Total \\
\hline \multicolumn{5}{|c|}{ Background characteristics } \\
\hline \multirow[t]{7}{*}{ Age group (in 2006) } & Under 65 & 55.3 & 66.4 & 55.7 \\
\hline & $65-75$ & 26.1 & 23.5 & 26.0 \\
\hline & $75+$ & 18.6 & 10.2 & 18.3 \\
\hline & Total (\%) & 100.0 & 100.0 & 100.0 \\
\hline & Weighted N & 2942.4 & 126.8 & 3069.2 \\
\hline & Observations & (3488) & (159) & $(3647)$ \\
\hline & $\mathbf{P}$ & 0.027 & & \\
\hline \multirow[t]{6}{*}{ Gender } & Male & 46.3 & 48.9 & 46.4 \\
\hline & Female & 53.7 & 51.1 & 53.6 \\
\hline & Total (\%) & 100.0 & 100.0 & 100.0 \\
\hline & Weighted N & 2942.4 & 126.8 & 3069.2 \\
\hline & Observations & (3488) & (159) & $(3647)$ \\
\hline & $\mathbf{P}$ & 0.578 & & \\
\hline \multicolumn{5}{|c|}{ Markers of transition to adulthood } \\
\hline \multirow[t]{6}{*}{ Parenthood status } & Childless & 9.5 & 28.7 & 10.3 \\
\hline & Parent & 90.5 & 71.3 & 89.7 \\
\hline & Total (\%) & 100.0 & 100.0 & 100.0 \\
\hline & Weighted N & 2942.4 & 126.8 & 3069.2 \\
\hline & Observations & (3488) & (159) & (3647) \\
\hline & $\mathbf{P}$ & $<0.001$ & & \\
\hline \multirow[t]{6}{*}{ Ever cohabited } & No & 3.0 & 5.0 & 3.1 \\
\hline & Yes & 97.0 & 95.0 & 96.9 \\
\hline & Total (\%) & 100.0 & 100.0 & 100.0 \\
\hline & Weighted N & 2942.4 & 126.8 & 3069.2 \\
\hline & Observations & (3488) & (159) & $(3647)$ \\
\hline & $\mathbf{P}$ & 0.142 & & \\
\hline \multirow[t]{6}{*}{ Ever been employed } & No & 0.2 & 0.8 & 0.2 \\
\hline & Yes & 99.8 & 99.2 & 99.8 \\
\hline & Total (\%) & 100.0 & 100.0 & 100.0 \\
\hline & Weighted N & 2942.4 & 126.8 & 3069.2 \\
\hline & Observations & (3488) & (159) & $(3647)$ \\
\hline & $\mathbf{P}$ & 0.237 & & \\
\hline \multirow[t]{6}{*}{ Ever left parental home } & No & 1.1 & 0.5 & 1.0 \\
\hline & Yes & 98.9 & 99.5 & 99.0 \\
\hline & Total (\%) & 100.0 & 100.0 & 100.0 \\
\hline & Weighted N & 2942.4 & 126.8 & 3069.2 \\
\hline & Observations & (3488) & (159) & (3647) \\
\hline & $\mathbf{P}$ & 0.490 & & \\
\hline
\end{tabular}


Table 1: Cont.

\begin{tabular}{|c|c|c|c|c|}
\hline \multicolumn{5}{|l|}{$\begin{array}{l}\text { Health trajectories and life course } \\
\text { turning events }\end{array}$} \\
\hline \multirow{6}{*}{$\begin{array}{l}\text { Ever been sexually assaulted (incl. } \\
\text { rape and harassment) }\end{array}$} & No & 94.0 & 88.2 & 93.8 \\
\hline & Yes & 6.0 & 11.8 & 6.2 \\
\hline & Total (\%) & 100.0 & 100.0 & 100.0 \\
\hline & Weighted N & 2573.7 & 105.8 & 2679.5 \\
\hline & Observations & $(3056)$ & $(136)$ & (3192) \\
\hline & $\mathbf{P}$ & 0.007 & & \\
\hline \multirow[t]{6}{*}{ Ever been physically assaulted } & No & 6.6 & 6.9 & 6.7 \\
\hline & Yes & 93.4 & 93.1 & 93.3 \\
\hline & Total (\%) & 100.0 & 100.0 & 100.0 \\
\hline & Weighted N & 2576.4 & 104.8 & 2681.2 \\
\hline & Observations & (3057) & $(135)$ & (3192) \\
\hline & P & 0.904 & & \\
\hline \multirow[t]{6}{*}{ Ever experienced financial hardship } & No & 82.6 & 75.4 & 82.3 \\
\hline & Yes & 17.4 & 24.6 & 17.7 \\
\hline & Total (\%) & 100.0 & 100.0 & 100.0 \\
\hline & Weighted N & 2457.3 & 102.5 & 2559.8 \\
\hline & Observations & (2927) & $(132)$ & (3059) \\
\hline & $\mathbf{P}$ & 0.072 & & \\
\hline \multirow[t]{6}{*}{ Ever been a daily smoker } & No & 40.2 & 41.8 & 40.3 \\
\hline & Yes & 59.8 & 58.2 & 59.7 \\
\hline & Total (\%) & 100.0 & 100.0 & 100.0 \\
\hline & Weighted N & 2856.0 & 121.3 & 2977.4 \\
\hline & Observations & (3381) & $(152)$ & (3533) \\
\hline & $\mathbf{P}$ & 0.714 & & \\
\hline \multicolumn{5}{|l|}{ Markers of transition to older age } \\
\hline \multirow{6}{*}{$\begin{array}{l}\text { Ever experienced serious illness or } \\
\text { accident }\end{array}$} & No & 75.2 & 78.8 & 75.4 \\
\hline & Yes & 24.8 & 21.2 & 24.6 \\
\hline & Total (\%) & 100.0 & 100.0 & 100.0 \\
\hline & Weighted N & 2515.6 & 105.8 & 2621.4 \\
\hline & Observations & (2989) & $(136)$ & (3125) \\
\hline & $\mathbf{P}$ & 0.413 & & \\
\hline \multirow[t]{6}{*}{ Ever retired (by 2012) } & No & 15.2 & 16.3 & 15.2 \\
\hline & Yes & 84.8 & 83.7 & 84.8 \\
\hline & Total (\%) & 100.0 & 100.0 & 100.0 \\
\hline & Weighted N & 2491.9 & 99.3 & 2591.2 \\
\hline & Observations & (2992) & (129) & (3121) \\
\hline & $\mathbf{P}$ & 0.741 & & \\
\hline \multirow{6}{*}{$\begin{array}{l}\text { Ever provided care for close friend or } \\
\text { relative }\end{array}$} & No & 79.8 & 70.2 & 79.5 \\
\hline & Yes & 20.2 & 29.8 & 20.5 \\
\hline & Total (\%) & 100.0 & 100.0 & 100.0 \\
\hline & Weighted N & 2489.2 & 100.1 & 2589.3 \\
\hline & Observations & $(2960)$ & $(129)$ & (3089) \\
\hline & $\mathbf{P}$ & 0.024 & & \\
\hline
\end{tabular}




\section{Timing of transitions to adulthood}

Results from Kaplan-Meier survival curves show that the age at which the first quartile of heterosexual and LGB people experience the 'big five' transitions to adulthood is almost identical (table 2). This consistency holds for the median age for heterosexual and LGB people for age at first cohabitation (23 years), age on leaving the parental home (heterosexual 22, LGB 21 years), age on leaving full-time education (15 years) and age on entry to the labour market (15 years). However, the median age at first parenthood occurs three years later for LGB people at 29 years compared to heterosexual people (26 years). Later entry to parenthood is also confirmed in table 3 when accounting for age and gender as potential confounders, with a time ratio of 1.13 observed for LGB people compared to heterosexual people. While this is a statistically significant difference, the result nevertheless suggests that family formation is a frequently occurring transition experience for many LGB people.

Table 2: Age at first quartile/median age of experiencing five transitions to adulthood by sexual orientation (years)

\begin{tabular}{|c|c|c|c|c|}
\hline & \multicolumn{2}{|c|}{ Heterosexual } & \multicolumn{2}{|c|}{ Lesbian, gay or bisexual } \\
\hline & First quartile & Median & First quartile & Median \\
\hline $\begin{array}{l}\text { Age at first } \\
\text { parenthood }\end{array}$ & 23 & 26 & 23 & 29 \\
\hline $\begin{array}{l}\text { Age at first } \\
\text { cohabiting } \\
\text { partnership }\end{array}$ & 21 & 23 & 20 & 23 \\
\hline $\begin{array}{l}\text { Age on leaving } \\
\text { parental home }\end{array}$ & 19 & 22 & 19 & 21 \\
\hline $\begin{array}{l}\text { Age left full-time } \\
\text { education }\end{array}$ & 15 & 16 & 15 & 16 \\
\hline $\begin{array}{l}\text { Age entered labour } \\
\text { market }\end{array}$ & 15 & 16 & 15 & 16 \\
\hline $\begin{array}{l}\mathrm{N} \text { (obs)/ N } \\
\text { (weighted) }\end{array}$ & \multicolumn{2}{|c|}{3488 (2942.4) } & \multicolumn{2}{|c|}{$159(126.8)$} \\
\hline
\end{tabular}


Table 3: Time ratios from log-logistic accelerated failure time models for transitions to adulthood

\begin{tabular}{ccccc}
\hline $\begin{array}{c}\text { Age at first } \\
\text { parenthood }\end{array}$ & $\begin{array}{c}\text { Age at first } \\
\text { cohabiting } \\
\text { relationship }\end{array}$ & $\begin{array}{c}\text { Age at first } \\
\text { employment }\end{array}$ & $\begin{array}{c}\text { Age left } \\
\text { education }\end{array}$ & $\begin{array}{c}\text { Age left parental } \\
\text { home }\end{array}$ \\
\hline
\end{tabular}

Sexual orientation (base: heterosexual)

\begin{tabular}{lcccccccccc} 
& $\begin{array}{c}\text { Un- } \\
\text { adjusted }\end{array}$ & Adjusted & $\begin{array}{c}\text { Un- } \\
\text { adjusted }\end{array}$ & Adjusted & $\begin{array}{c}\text { Un- } \\
\text { adjusted }\end{array}$ & Adjusted & $\begin{array}{c}\text { Un- } \\
\text { adjusted }\end{array}$ & Adjusted & $\begin{array}{c}\text { Un- } \\
\text { adjusted }\end{array}$ & Adjusted \\
\hline $\begin{array}{l}\text { Lesbian, } \\
\text { Gay or }\end{array}$ & $1.126^{*}$ & $1.130^{* *}$ & 1.011 & 1.014 & $1.030^{*}$ & 1.022 & $1.031^{*}$ & 1.022 & 0.972 & 0.981 \\
Bisexual & & & & & & & & & & \\
& $(0.047)$ & $(0.047)$ & $(0.021)$ & $(0.019)$ & $(0.012)$ & $(0.011)$ & $(0.012)$ & $(0.011)$ & $(0.019)$ & $(0.017)$
\end{tabular}

\section{Gender (base: Male)}

\begin{tabular}{lccccc} 
Female & $0.890^{* * *}$ & $0.901^{* * *}$ & 0.994 & 0.994 & $0.952^{* * *}$ \\
& $(0.008)$ & $(0.006)$ & $(0.003)$ & $(0.003)$ & $(0.007)$ \\
\hline
\end{tabular}

Age group (base: 50-64)

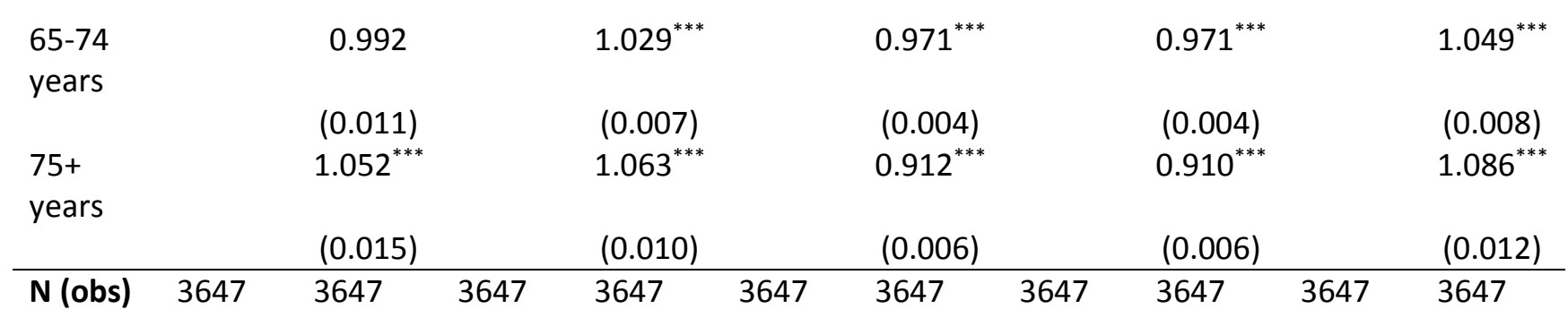

Exponentiated coefficients (Time ratios: values over one indicate a slower transition to the event; standard error of unexponentiated coefficients in parentheses)

${ }^{*} p<0.05,{ }^{* *} p<0.01,{ }^{* * *} p<0.001$ 
Health trajectories and life course turning points

Earlier results suggested that many of the transitions to adulthood and ageing were experienced at similar points among LGB and heterosexual people; table 4 examines life course events that occur between transitions to adulthood and older age. In the unadjusted models, we found that LGB people had an increased risk of experiencing severe financial hardship at earlier age (borderline statistically significant; $p=0.06$ ), though this effect attenuated once we control for age and gender. However, the magnitude of the coefficient, which showed a substantial difference, changed very little; this could suggest in a larger sample this apparent difference may be robust to other factors. LGB people's risk of sexual assault (including harassment and rape) remained much higher and occurred earlier in the life course than for non-LGB people, even after accounting for age and gender. Kaplan-Meier survival curves (shown in supplement), find that by the age of $15,5 \%$ of LGB people reported experiencing sexual assault and by the age of $23,10 \%$ did so; by age 24 years, $5 \%$ of heterosexual people had experienced sexual assault and the point at which $10 \%$ experienced assault was not observed in these data. The risk of physical assault was not statistically different for LGB individuals, similarly no differences were observed in the risk of becoming a daily smoker, despite population-level studies suggesting LGB adults are at greater risk of smoking than non-LGB people (Gruskin, Greenwood, Matevia, Pollack, \& Bye, 2007).

Table 4: Time ratios from log-logistic accelerated failure time models for markers of life course turning points

\begin{tabular}{cccc}
\hline $\begin{array}{c}\text { Age at first sexual } \\
\text { assault }\end{array}$ & $\begin{array}{c}\text { Age at first physical } \\
\text { assault }\end{array}$ & $\begin{array}{c}\text { Age at first } \\
\text { experience of severe } \\
\text { financial hardship }\end{array}$ & $\begin{array}{c}\text { Age first smoked on a } \\
\text { daily basis }\end{array}$ \\
\hline
\end{tabular}

\section{Sexual orientation (base: heterosexual)}

\begin{tabular}{lcccccccc} 
& Unadjusted & Adjusted & Unadjusted & Adjusted & Unadjusted & Adjusted & Unadjusted & Adjusted \\
\hline $\begin{array}{l}\text { Lesbian, } \\
\text { Gay or }\end{array}$ & $0.349^{* *}$ & $0.426^{*}$ & 0.923 & 1.003 & 0.696 & 0.754 & 1.057 & 1.073 \\
$\begin{array}{l}\text { Bisexual } \\
\end{array}$ & & & & & & & & \\
& $(0.385)$ & $(0.364)$ & $(0.134)$ & $(0.092)$ & $(0.194)$ & $(0.186)$ & $(0.124)$ & $(0.120)$ \\
\hline
\end{tabular}

\section{Gender (base: Male)}

Female

\section{Age group (base: $50-64$ )}

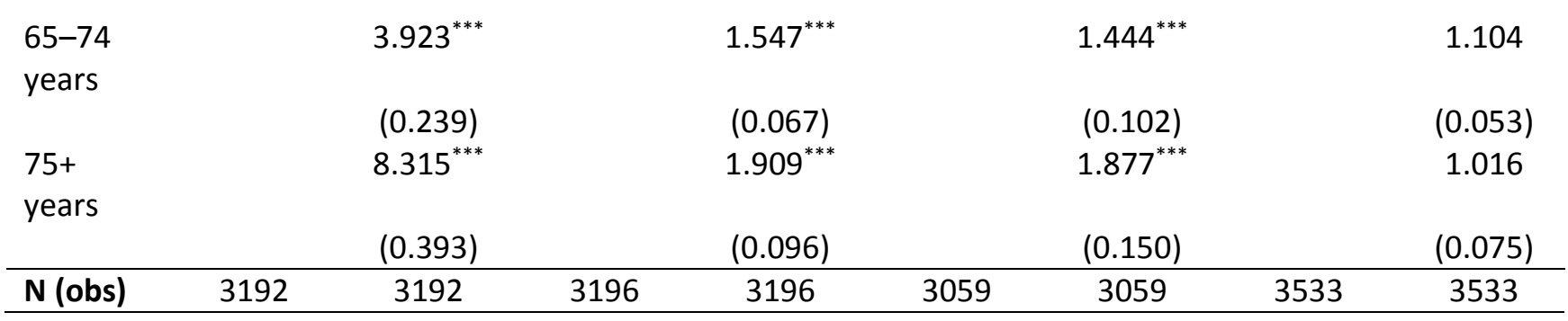

Exponentiated coefficients (Time ratios: values over one indicate a slower transition to the event; standard error of unexponentiated coefficients in parentheses)

${ }^{*} p<0.05,{ }^{* *} p<0.01,{ }^{* * *} p<0.001$ 


\section{Timing of 'ageing' life course events}

We see that LGB people retire earlier than nonLGB people, with the age first quartile occurring two years earlier at 56 years for LGB people compared with 58 years for heterosexual. However, these differences do not remain when we consider the median age of first occurrence or when we control for differences in the age and gender profile (tables 5 and 6). We see similar ages for first incidence of experiencing a serious illness or accident. However we see that experiences of ill-health disproportionately featured in the ageing trajectories of LGB people due to earlier experiences of providing care. The age at which the first quartile of LGB people started to provide care for a relative or close friend occurred 21 years earlier, at 54 years, than for heterosexual people (75 years). This difference remained after accounting for sample differences in age and gender, so that the times before which LGB people became carers were approximately $20 \%$ shorter than among non-LGB people (table 6).

Table 5: Age at first quartile/median age of experiencing retirement transitions by sexual orientation (years)

\begin{tabular}{|c|c|c|c|c|}
\hline & \multicolumn{2}{|c|}{ Heterosexual } & \multicolumn{2}{|c|}{ Lesbian, gay or bisexual } \\
\hline & First quartile & Median & First quartile & Median \\
\hline $\begin{array}{l}\text { Age at first serious } \\
\text { illness or accident }\end{array}$ & 68 & - & 67 & - \\
\hline $\begin{array}{l}\mathrm{N} \text { (obs)/ N } \\
\text { (weighted) }\end{array}$ & \multicolumn{2}{|c|}{$2989(2516)$} & \multicolumn{2}{|c|}{$136(105.8)$} \\
\hline Age at retirement & 58 & 60 & 56 & 60 \\
\hline $\begin{array}{l}\text { N (obs)/ N } \\
\text { (weighted) }\end{array}$ & \multicolumn{2}{|c|}{2992 (2492) } & \multicolumn{2}{|c|}{129 (99.3) } \\
\hline $\begin{array}{l}\text { Age first provided } \\
\text { care for relative or } \\
\text { close friend }\end{array}$ & 75 & - & 54 & - \\
\hline $\begin{array}{l}\mathrm{N} \text { (obs)/ N } \\
\text { (weighted) }\end{array}$ & \multicolumn{2}{|c|}{2960 (2489) } & \multicolumn{2}{|c|}{129 (100.1) } \\
\hline
\end{tabular}

Where ' - ' indicates that percentile does not experience the event. 
Table 6: Time ratios from log-logistic accelerated failure time models for transitions to older age

Age at first serious illness

Age at retirement

Age first provided care to a relative or close friend

Sexual orientation (base: heterosexual)

\begin{tabular}{lcccccc} 
& Unadjusted & Adjusted & Unadjusted & Adjusted & Unadjusted & Adjusted \\
\hline $\begin{array}{l}\text { Lesbian, Gay or } \\
\text { Bisexual }\end{array}$ & 1.181 & 1.217 & 0.986 & 0.987 & $0.788^{* *}$ & $0.806^{* *}$ \\
& & & & & & \\
& $(0.235)$ & $(0.230)$ & $(0.011)$ & $(0.011)$ & $(0.081)$ & $(0.078)$
\end{tabular}

Gender (base: Male)

Female

$\begin{array}{lcc}1.370^{* * *} & 0.962^{* * *} & 0.774^{* * *} \\ (0.086) & (0.003) & (0.036)\end{array}$

Age group (base: 50-64)

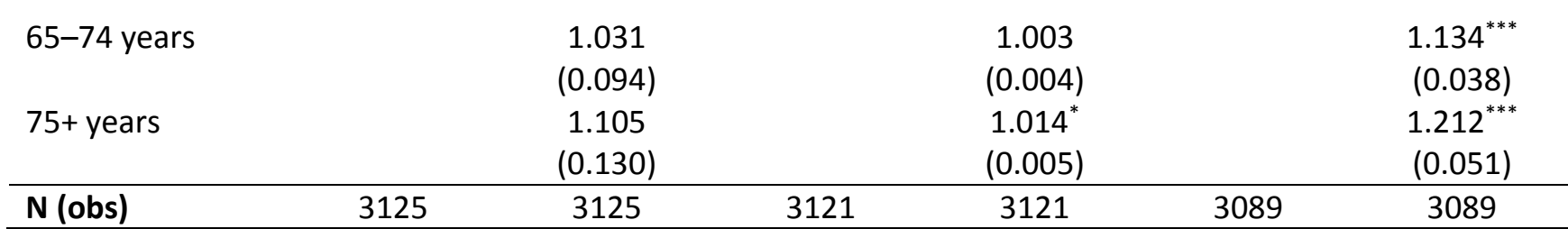

Exponentiated coefficients (Time ratios: values over one indicate a slower transition to the event; standard error of unexponentiated coefficients in parentheses)

${ }^{*} p<0.05,{ }^{* *} p<0.01,{ }^{* * *} p<0.001$

\section{Alternative definitions of LGB}

We conducted sensitivity analyses exploring the impact of using alternative definitions LGB status (see supplementary material for details) on those variables where being LGB patterned the frequency or tempo of transitions experienced. Alternative definitions showed LGB people as having similar experiences in terms of later/lower levels of parenthood and earlier/increased risks of sexual assault and financial hardship, and an earlier age of providing care for friends or family. However, for both alternative definitions, differences from heterosexuals did not remain statistically significant when age and gender covariates were added in the models for sexual assault, financial hardship and provision of care (see supplementary material). In the case of experiences of sexual assault and financial hardship, the magnitude of the coefficients suggested some differences, although the models may have been underpowered, particularly to explore interaction effects. In the case of provision of care, the magnitude of coefficients also attenuated with adjustment for covariates.
Differences in transitions to parenthood remain robust to alternative definitions of LGB status and alternative categorisations of sexuality also reveal differences in the tempo of experiencing financial hardship and sexual assault by sexual orientation, but these differences do not remain statistically significant in adjusted models. Descriptive analyses using Kaplan-Meier survival curves, disaggregated by gender or age cohort with alternative measures of sexuality also demonstrate that LGB people experience lower and later parenthood. They also show that particular LGB groups experience earlier and more frequent experiences of sexual assault, provision of care, and financial hardship (see supplement). However, these charts also suggest that interaction terms might better capture this variation or intersectionality, which the analytical sample sizes included in these models do not support.

Differences between the analyses that form the mainstay of this study and those in the sensitivity analyses are driven by classification choice of a small group of individuals who have experienced 
some same-sex activity, but report exclusively opposite sex desires across the life course. In the main analyses included here (table 2 onwards) this group are classified as LGB, but are classified in the definitions used in the sensitivity analyses as nonLGB. Among those with information on transitions to adulthood, this group includes 47 individuals (weighted down to 36), 37\% of whom are women and $89 \%$ were aged $50-64$ years. Despite the gender imbalance towards men, it was females in this group who reported noticeably high levels of sexual assault ( $39 \%$ vs $14 \%$ ), provision of care $(63 \%$ vs $33 \%$ ), and financial hardship ( $37 \%$ vs $31 \%$ ). Based on these analyses, individuals who have experienced same-sex contact, but not same-sex desire, appear particularly vulnerable to some of the adverse transitions explored here, particularly among women, albeit with caveats around the extremely small sample sizes. We are unable to comment whether the same-sex experience, which in this case is reported as being unaccompanied by desire, is consensual or non-consensual. Elsewhere, other studies have speculated that some older people reporting early same-sex experience that was not carried through into later adulthood may be reporting on experiences of abuse, particularly among men (Layte et al., 2006). This explanation may not apply fully in this case, particularly given differential gender profile reporting adverse events, and given that the time of same-sex contact cannot be established, although this possibility cannot be fully discounted either.

Other studies have found that adolescents and adults who experience same-sex sexual contact, but report no same-sex desires (Zhao, Montoro, Igartua, \& Thombs, 2010) or heterosexual identification (Schrimshaw, Siegel, Downing Jr, \& Parsons, 2013), are at risk of adverse outcomes (mental health outcomes in both studies cited). From an analytical perspective, is remains unclear whether this group should be included as 'LGB' or not in the analyses, highlighting the challenge, and pitfalls, of attempting to impose an 'essentialist' perspective on sexuality (Layte et al., 2006). Again, a larger sample would allow greater flexibility and sensitivity in the way in which LGB is defined.

\section{Discussion}

\section{Key findings}

These results suggest that LGB life course trajectories exhibit elements of both convergence and divergence with those of heterosexual peers.
Both LGB and non-LGB people exhibit a surprising uniformity in early trajectories, reaching the first quartile milestone at which the 'big five' transitions to adulthood are experienced within a year of each other. Differences begin to open up at this point in terms of family formation patterns being experienced later, with the median age at first parenthood occurring six years later for LGB people at age 29 years, and ultimately this postponement does indicate fewer parents among LGB people by the age of 50. Retirement and the age at which people experience a serious illness also show a remarkable degree of uniformity across groups in tempo, although caring duties appear to feature much earlier in the life course of LGB people, and particularly non-heterosexual women (see supplementary materials). However, this earlier transition to a caring role does not lead to earlier exits from the labour market for LGB people, despite caring being linked to earlier retirement (King \& Pickard, 2013). In addition to differences in family formation and caring patterns, there are indications that LGB people reach older age having experienced severe financial hardship at earlier ages (not statistically significant), and have been much more likely to have experienced trauma through sexual assault, although this latter finding is sensitive to the definition of sexuality used. While the baseline risk of experiencing sexual assault is relatively low for both groups, and lower than might be expected given the estimates of attempted and actual non-volitional sex found among older people elsewhere (Macdowall et al., 2013), the potential increased risk for LGB people appears substantial and non-ignorable.

\section{Limitations}

The results presented here are accompanied by four caveats. The first of these is the size of the sample, and the small group of LGB people that were identified and upon which these analyses are based. By its very nature, the small sample increases the risk of type II errors but also meant that we were unable include a robust set of controls for known differences between LGB and non-LGB populations, such as socioeconomic differences (Uhrig, 2015), to avoid overfitting models. This meant that we were unable to disaggregate differences between lesbian, gay or bisexual men and women. As the sensitivity and descriptive analyses presented in the supplementary appendix 
file show, there are likely to be substantial differences across the LGB spectrum.

A second caveat is around our method of classifying people as 'LGB'. Sexuality is a highly complex construct that is found to be fluid across the life course. Assumptions that sexual identification is fixed by older age are unfounded (Knocker, 2012), and some of the results appeared particularly sensitive to the presence of a small group of people whose sexuality may not be best represented through a binary indicator, as was the case in these models.

The third caveat was in our choice of indicators, which arguably attempted to impose a heteronormative lens onto the life course of LGB people. In particular, markers of a 'full' transition to adulthood will hold different significance to older LGB people, particularly with respect to family formation (Westwood, 2013). The very way in which life course markers of transitions to adulthood and ageing are selected may need adapting to avoid imposing heteronormative conceptions of successful and complete transitions when understanding LGB lives (Cronin \& King, 2014). This is an important consideration, although the analyses here can also be viewed as providing a descriptive account of the convergence and divergence of life course trajectories when imposing what is essentially a heteronormative framework of measuring youth and ageing transitions. Many of the markers explored here do appear to resonate and have significance in the lives of this sample of LGB older people. However, this doesn't negate that other markers not explored here may hold equal or greater significance in exploring LGB life course trajectories, and may differ substantially according to the groups contained within the acronym itself.

The fourth caveat is in our own interpretation of the results and the difficulty in generalising the findings. While we refer to these results as being germane to the lives of people aged 50 and over (in 2006), the applicability of the findings is limited in the ways described above because of the small sample and the heterogeneity among LGB people. The generalisability of the results is also impeded by the influence of context that may be driving these results. It is unclear the extent to which shifting contexts in social norms will impact on family formation patterns of LGB people who are currently experiencing transitions to adulthood. As we witnessed in debates around same-sex marriage in the UK and elsewhere, for example, for some, societal acceptance is congruent with 'assimilation' into structures and experiences that were previously restricted, while for others societal acceptance is hinged on difference and opportunities to express and celebrate difference (Walther, 2015); for most others this distinction is context dependent.

\section{Future research}

The opportunities for identifying LGB people in large-scale surveys have expanded and this is to be welcomed. However, this is not necessarily congruent with opportunities to robustly study LGB life course patterns, and to comparatively understand the needs of LGB people at different life course stages. This paper has made a contribution to this end through presenting evidence of convergence and divergence at different stages and across different markers. However, these analyses alone are insufficient to provide an evidence-based case for the type of support that LGB people may need in navigating different life course transitions. Nevertheless, they do provide the basis for further enquiry and provide early indications as to the challenges that LGB people may face in comparison to their heterosexual peers, particularly around experiences of care giving, experience of severe trauma (sexual assault) and potentially around differential levels of reciprocal support available in older age from children. To maximise investments in existing surveys, future enquiry could focus on developing ways of exploiting the small pockets of data on LGB people held across different large-scale surveys. This is in order for the avenues of enquiry outlined above to be pursued across different age, gender and socioeconomic intersectionalities without statistical power being a perfunctory restriction to meaningful analysis, as is arguably the case in most extant quantitative literature. Some of this may involve critically examining the applicability of methods developed in systematic review literature and particularly Individual Participant Data (IPD) meta-analysis (Tierney et al., 2015), which may provide future analyses with sufficient statistical power to better understand the many remaining substantive questions about the comparative nature of LGB life course trajectories. 


\section{Acknowledgements}

The authors acknowledge support in completion of later stages of this paper from a Wellcome Trust grant (207986/Z/17/Z) on 'Using new evidence synthesis techniques to explore health and care inequalities among Lesbian, Gay, Bisexual and Transgender people'.

\section{References}

Addis, S., Davies, M., Greene, G., MacBride-Stewart, S., \& Shepherd, M. (2009). The health, social care and housing needs of lesbian, gay, bisexual and transgender older people: A review of the literature. Health \& Social Care in the Community, 17(6), 647-658. https://doi.org/10.1111/j.1365$\underline{2524.2009 .00866 . x}$

Arnett, J. J. (2000). Emerging adulthood: A theory of development from the late teens through the twenties. American Psychologist, 55(5), 469. https://doi.org/10.1037/0003-066X.55.5.469

Arnett, J. J. (2003). Conceptions of the transition to adulthood among emerging adults in American ethnic groups. New Directions for Child and Adolescent Development, 2003(100), 63-76. https://doi.org/10.1002/cd.75

Bynner, J. (2005). Rethinking the youth phase of the life-course: The case for emerging adulthood? Journal of Youth Studies, 8(4), 367-384. https://doi.org/10.1080/13676260500431628

Chudacoff, H. P., \& Hareven, T. K. (1979). From the empty nest to family dissolution: Life course transitions into old age. Journal of Family History, 4(1), 69. https://doi.org/10.1177/036319907900400105

Cronin, A., \& King, A. (2014). Only connect? Older lesbian, gay and bisexual (LGB) adults and social capital. Ageing and Society, 34(02), 258-279. 02), 258-279.

https://doi.org/10.1017/S0144686X12000955

Dannefer, D. (2003). Cumulative advantage/disadvantage and the life course: Cross-fertilizing age and social science theory. The Journals of Gerontology Series B: Psychological Sciences and Social Sciences, 58(6), S327-S337. https://doi.org/10.1093/geronb/58.6.S327

Fredriksen-Goldsen, K. I., Emlet, C. A., Kim, H.-J., Muraco, A., Erosheva, E. A., Goldsen, J., \& Hoy-Ellis, C. P. (2013). The physical and mental health of lesbian, gay male, and bisexual (LGB) older adults: The role of key health indicators and risk and protective factors. The Gerontologist, 53(4), 664-675. https://doi.org/10.1093/geront/gns123

Fredriksen-Goldsen, K. I., \& Muraco, A. (2010). Aging and sexual orientation: A 25-year review of the literature. Research on Aging, 32(3), 372-413. https://doi.org/10.1177/0164027509360355

French, R., \& Steele, F. (2015). Trajectories of functional disability for the elderly in Britain. Longitudinal and Life Course Studies, 6(3). https://doi.org/10.14301/llcs.v6i3.317

Furstenberg, F. F. J. (2010). On a new schedule: Transitions to adulthood and family change. The future of children, 20(1), 67-87. https://doi.org/10.1353/foc.0.0038

Geronimus, A. T. (2003). Damned if you do: Culture, identity, privilege, and teenage childbearing in the United States. Social Science \& Medicine, 57(5), 881-893. https://doi.org/10.1016/S02779536(02)00456-2

Geronimus, A. T. (2004). Teenage childbearing as cultural prism. British Medical Bulletin, 69(1), 155-166. https://doi.org/10.1093/bmb/ldh019

Green, M. (2016). Do the companionship and community networks of older LGBT adults compensate for weaker kinship networks? Quality in Ageing and Older Adults, 17(1), 36-49. https://doi.org/10.1108/QAOA-07-2015-0032

Gruskin, E. P., Greenwood, G. L., Matevia, M., Pollack, L. M., \& Bye, L. L. (2007). Disparities in smoking between the lesbian, gay, and bisexual population and the general population in California. American Journal of Public Health, 97(8), 1496-1502. https://doi.org/10.2105/AJPH.2006.090258

Hammack, P. L., \& Cohler, B. J. (2011). Narrative, identity, and the politics of exclusion: Social change and the gay and lesbian life course. Sexuality Research and Social Policy, 8(3), 162-182. https://doi.org/10.1007/s13178-011-0060-3 
Harrison, J. (2006). Coming out ready or not! Gay, lesbian, bisexual, transgender and intersex ageing and aged care in Australia: Reflections, contemporary developments and the road ahead. Gay and Lesbian Issues and Psychology Review, 2(2), 44-53.

Henderson, M. (2015). Understanding Bullying Experiences among Sexual Minority Youths in England. Retrieved from London: http://www.cls.ioe.ac.uk/shared/getfile. ashx?itemtype $=$ document\&id $=3116$

Hughes, M. E., Waite, L. J., LaPierre, T. A., \& Luo, Y. (2007). All in the family: The impact of caring for grandchildren on grandparents' health. The Journals of Gerontology Series B: Psychological Sciences and Social Sciences, 62(2), S108-S119. https://doi.org/10.1093/geronb/62.2.S108

Jenkins, S. P. (2005). Survival Analysis. Retrieved from Colchester, Essex: http://citeseerx.ist.psu.edu/viewdoc/download?doi=10.1.1.176.7572\&rep=rep1\&type=pdf

Kaplan, E., \& Meier, P. (1958). Nonparametric estimation from incomplete observations. Journal of the American Statistical Association, 53(282), 457-481. https://doi.org/10.1080/01621459.1958.10501452

Kim, J. E., \& Moen, P. (2002). Retirement transitions, gender, and psychological well-being a life-course, ecological model. The Journals of Gerontology Series B: Psychological Sciences and Social Sciences, 57(3), P212-P222. https://doi.org/10.1093/geronb/57.3.P212

King, D., \& Pickard, L. (2013). When is a carer's employment at risk? Longitudinal analysis of unpaid care and employment in midlife in England. Health \& Social Care in the Community, 21(3), 303-314. https://doi.org/10.1111/hsc.12018

Kneale, D. (2016). Connected communities? LGB older people and their risk of exclusion from decent housing and neighbourhoods. Quality in Ageing and Older Adults, 17(2), 107-118. https://doi.org/10.1108/QAOA-04-2015-0019

Kneale, D., \& Joshi, H. (2010). Postponement and childlessness: evidence from two British cohorts. Demographic Research, 19, 1935. https://doi.org/10.4054/DemRes.2008.19.58

Kneale, D., Sholl, P., Sherwood, C., \& Faulkner, J. (2014). Ageing and lesbian, gay and bisexual relationships. Working with Older People, 18(3), 142-151. https://doi.org/10.1108/WWOP-06-2014-0015

Knocker, S. (2012). Perspectives on ageing: lesbians, gay men and bisexuals. York: Joseph Rowntree Foundation.

Kuh, D., \& NDAP Network. (2007). A life course approach to healthy aging, frailty, and capability. The Journals of Gerontology Series A: Biological Sciences and Medical Sciences, 62(7), 717-721. https://doi.org/10.1093/gerona/62.7.717

Layte, R., McGee, H., Quail, A., Rundle, K., Cousins, G., Donnelly, C., . . Conroy, R. (2006). The Irish study of sexual health and relationships (Main Report) (1905199082). Retrieved from Dublin: http://www.ucd.ie/issda/static/documentation/esri/isshr-report.pdf

Lee, D. M., Nazroo, J., O'Connor, D. B., Blake, M., \& Pendleton, N. (2015). Sexual Health and Well-being Among Older Men and Women in England: Findings from the English Longitudinal Study of Ageing. Archives of Sexual Behavior, 1-12.

Lehavot, K., \& Simoni, J. M. (2011). The impact of minority stress on mental health and substance use among sexual minority women. Journal of Consulting and Clinical Psychology, 79(2), 159. https://doi.org/10.1037/a0022839

Lupton, R., Tunstall, R., Sigle-Rushton, W., Obolenskaya, P., Sabates, R., Meschi, E., . . Salter, E. (2009). Growing up in social housing in Britain: a profile of four generations from 1946 to the present day. York: Joseph Rowntree Foundation. Retrieved from York: https://www.jrf.org.uk/sites/default/files/jrf/migrated/files/social-housing-britain-FULL.pdf

Macdowall, W., Gibson, L. J., Tanton, C., Mercer, C. H., Lewis, R., Clifton, S., . . Sonnenberg, P. (2013). Lifetime prevalence, associated factors, and circumstances of non-volitional sex in women and men in Britain: findings from the third National Survey of Sexual Attitudes and Lifestyles (Natsal-3). The Lancet, 382(9907), 1845-1855. https://doi.org/10.1016/S0140-6736(13)62300-4

Meyer, I. H. (1995). Minority stress and mental health in gay men. Journal of Health and Social Behavior, 3856. https://doi.org/10.2307/2137286 
Meyer, I. H. (2003). Prejudice, social stress, and mental health in lesbian, gay, and bisexual populations: conceptual issues and research evidence. Psychological Bulletin, 129(5), 674. https://doi.org/10.1037/0033-2909.129.5.674

Muraco, A., \& Fredriksen-Goldsen, K. I. (2016). Turning points in the lives of lesbian and gay adults age 50 and over. Advances in Life Course Research. 30(June):124-132. https://doi.org/10.1016/j.alcr.2016.06.002

Musingarimi, P. (2008). Housing Issues Affecting Older Gay, Lesbian and Bisexual People in the UK: A Policy Brief. Retrieved from London: http://www.ilcuk.org.uk/files/pdf pdf 69.pdf

Needham, B. L., \& Austin, E. L. (2010). Sexual orientation, parental support, and health during the transition to young adulthood. Journal of Youth and Adolescence, 39(10), 1189-1198. https://doi.org/10.1007/s10964-010-9533-6

Phillips, J., \& Marks, G. (2008). Ageing lesbians: Marginalising discourses and social exclusion in the aged care industry. Journal of Gay \& Lesbian Social Services, 20(1-2), 187-202. https://doi.org/10.1080/10538720802179237

Potter, C., Bamford, S., \& Kneale, D. (2011). Bridging the Gap: Exploring the Potential for bringing older and younger LGBT people together. Retrieved from London:

http://www.ilcuk.org.uk/index.php/publications/publication details/bridging the gap exploring th e potential for bringing older and younger lgb

Rindfuss, R. R., Morgan, S. P., \& Offutt, K. (1996). Education and the changing age pattern of American fertility: 1963-1989. Demography, 33(3), 277-290. https://doi.org/10.2307/2061761

Rogan, M., \& Reynolds, J. (2015). Schooling inequality, higher education and the labour market: Evidence from a graduate tracer study in the Eastern Cape, South Africa. Retrieved from Pretoria, South Africa:

https://www.ru.ac.za/media/rhodesuniversity/content/iser/documents/LMIP\%20Working\%20Paper \%202.pdf.

Schoon, I., Chen, M., Kneale, D., \& Jager, J. (2012). Becoming adults in Britain: lifestyles and wellbeing in times of social change. Longitudinal and Life Course Studies, 3(2), 173-189.

Schrimshaw, E. W., Siegel, K., Downing Jr, M. J., \& Parsons, J. T. (2013). Disclosure and concealment of sexual orientation and the mental health of non-gay-identified, behaviorally bisexual men. Journal of Consulting and Clinical Psychology, 81(1), 141. https://doi.org/10.1037/a0031272

Schulenberg, J., \& Schoon, I. (2012). The transition to adulthood across time and space: overview of Special Section. Longitudinal and Life Course Studies, 3(2),164.

Settersten Jr, R. A., \& Mayer, K. U. (1997). The measurement of age, age structuring, and the life course. Annual Review of Sociology, 233-261. https://doi.org/10.1146/annurev.soc.23.1.233

Shanahan, M. J. (2000). Pathways to adulthood in changing societies: Variability and mechanisms in life course perspective. Annual Review of Sociology, 667-692.

https://doi.org/10.1146/annurev.soc.26.1.667

Sigle, W. (2016). Fertility and Population Change in the United Kingdom. In R. R. Rindfuss \& M. K. Choe (Eds.), Low Fertility, Institutions, and their Policies (pp. 77-98). Springer.

Steptoe, A., Breeze, E., Banks, J., \& Nazroo, J. (2013). Cohort profile: the English longitudinal study of ageing. International Journal of Epidemiology, 42(6), 1640-1648. https://doi.org/10.1093/ije/dys168

Tierney, J. F., Pignon, J.-P., Gueffyier, F., Clarke, M., Askie, L., Vale, C. L., . . Group, C. I. M.-a. M. (2015). How individual participant data meta-analyses have influenced trial design, conduct, and analysis. Journal of Clinical Epidemiology, 68(11), 1325-1335. https://doi.org/10.1016/i.jclinepi.2015.05.024

Uhrig, S. (2015). Sexual orientation and poverty in the UK: A review and top-line findings from the UK household longitudinal study. J. Res. Gender Stud., 5, 23.

Utz, R. L., Carr, D., Nesse, R., \& Wortman, C. B. (2002). The effect of widowhood on older adults' social participation an evaluation of activity, disengagement, and continuity theories. The Gerontologist, 42(4), 522-533. https://doi.org/10.1093/geront/42.4.522 
Walther, C. S. (2015). The Marrying Kind?: Debating Same-Sex Marriage within the Lesbian and Gay Movement. Contemporary Sociology: A Journal of Reviews, 44(1), 35-37. https://doi.org/10.1177/0094306114562201d

Westwood, S. (2013). 'My Friends are my Family': an argument about the limitations of contemporary law's recognition of relationships in later life. Journal of Social Welfare and Family Law, 35(3), 347-363. https://doi.org/10.1080/09649069.2013.801688

Zhao, Y., Montoro, R., Igartua, K., \& Thombs, B. D. (2010). Suicidal ideation and attempt among adolescents reporting "unsure" sexual identity or heterosexual identity plus same-sex attraction or behavior: forgotten groups? Journal of the American Academy of Child \& Adolescent Psychiatry, 49(2), 104113.

\section{Endnotes}

1. However, the ELSA wave 6 data do not measure whether older people's gender identity has changed since the gender ascribed to them at birth.

2. The small number of asexual people identified (41) were excluded.

3. In the case of parenthood, if a logical inconsistency was provided for the first birth, values for the second were substituted in a small number of cases to attempt to preserve the size of the sample. Cases removed due to logical inconsistencies (including some that were 'don't knows') accounted for 15 parenthood histories; four cohabiting histories; seven employment histories; eight educational histories (including seven who did not attend school); and seven independent housing histories. 